NASA Technical Memorandum 106005

\title{
Modelling a Single Phase Voltage Controlled Rectifier Using Laplace Transforms
}

L. Alan Kraft Valparaiso University Valparaiso, Indiana and

M. David Kankam Lewis Research Center Cleveland, Ohio

Prepared for the

5th International Conference on Harmonics in Power Systems sponsored by the Institute of Electrical and Electronics Engineers Atlanta, Georgia, September 22-25, 1992 
$\quad \therefore-\cdots=-\quad-\quad-1=$ 


\section{MODELLING A SINGLE PHASE, VOLTAGE CONTROLLED RECTIFIER USING LAPLACE TRANSFORMS}

\author{
L. Alan Kraft \\ Valparaiso University \\ Senior Member
}

\author{
M. David Kankam \\ NASA, Lewis Research Center \\ Senior Member
}

\begin{abstract}
The development of a $20 \mathrm{kHz}, \mathrm{AC}$ power system by NASA for large space projects has spurred a need to develop models for the equipment which will be used on these single phase systems. To date, models for the AC source (i.e., inverters) have been developed. It is the intent of this paper to develop a method to model the single phase voltage controlled rectifiers which will be artached to the $A C$ power grid as an interface for connected loads. A modified version of EPRI's HARMFLO program is used as the shell for these models. The results obtained from the model developed in this paper are quite adequate for the analysis of problems such as voltage resonance. The unique technique presented in this paper uses the Laplace transforms to determine the harmonic content of the load current of the rectifier rather than a curve fitting technique. Laplace transforms yield the coefficients of the differential equations which model the line current to the rectifier directly.
\end{abstract}

\section{INTRODUCTION}

Plans for the further exploration of our solar system by NASA include the development of an orbiting space station (Freedom), a manned lunar base, and a manned mission to Mars. All of these programs will require large facilities- which are capable of supporting crews for long periods of time. The facilities must also suppon equipment required to maintain .communications, provide environmental needs, and power experimental instruments. To provide this energy, laroe capacity electrical power systems are required. The operation and design of these systems are very similar to terrestrial electric power systems with several subtle differences:

- the space power system will be single phase,

- the frequency of the power system will be $20 \mathrm{kHz}$ or higher, and

- the voltage will vary throughout the system. For example, semiconductors will be powered by voltages ranging from 10 to 100 V AC. Transmission voltage will be higher.

For these reasons, techniques developed for the design and analysis of terrestrial power systems are being adapted to space power systems.

The proposed frequency of space power systems is much higher than its terrestrial counterpart. Also, the planned space power distribution system will be single phase rather than three phase. The preference for a single phase system is based on its technical advantages. First, a single phase system eliminates the complexity of resolving potential faults as in multiphase redundant power distribution system. Secondly, the difficulty of schieving balanced, low impedance as in a mulxiphase transmission line is 
non-existent. The existence of nonlinear loads such as rectifiers will provide a potential for problems, such as harmonic distortions. To analyze these potential damaging conditions, existing software, such as HARMFLO [1-3] which was originally developed under the direction of EPRI for the analysis of terrestrial systems, has been modified for space applications. New models for the space components and subsystems have been developed and added to the software. Two such models, needed to provide a basis for the analysis of space power systems, relate to the source-end inverter and the major nonlinear load, namely, a voltage controlled rectifier.

The primary source of power on spacecraft may be anyone of a solar array and/or battery, a radioisotope thermoelectric generator (RTG), or a solar dynamic power system. A connected inverter converts the DC energy from sources, such as solar arrays and battery, to AC power for more efficiency and diversity. One proposed converter is that of a resonant Mapham inverter. Generally, a filter on the input side of the Mapham inverter ensures a reasonably clean DC voltage to the inverter input terminals. Typically, the switching frequency, $f_{\text {ow }}$ is less than the resonant frequency, $f_{\mathrm{ra}}$. If $f_{\mathrm{m}}$ and $f_{\text {m. }}$ are not significantly different in value, then the conduction mode of the thyristors is continuous. This yields a near sinusoidal output of the inverter. However, if $f_{\text {, }}$ far exceeds $f_{\mathrm{m}}$ then the output becomes discontinuous and causes harmonic distortion. The techniques used to model an inverter for a harmonic power flow (HARMFLO) have been described in previous publications $[4,5]$.

Since voltage controlled, full wave rectifiers require the switching of the load current, it is also a source of harmonic distortion. The techniques used to model a single phase rectifier for HARMFLO is the focus of this paper.

\section{OPERATION OF THE RECTIFIER}

The circuit diagram of a single phase, voltage controlled rectifier is shown in Figure 1 . Since the DC output voltage of the rectifier is the RMS value of the voltage waveform, $V_{0}$, shown in Figure 2. it can be controlled by changing the firing angle, $a$. This means that, by adjusting $a$, the RMS value of the DC output voltage can be controlled within limits. The value of $\sigma$ is determined, thus, by the difference between the desired and actual DC output voltages. Once either of the SCR's is triggered, it will conduct until the voltage on the anode is less than the voltage on the cathode. This occurs when the voltage on the transformer side of the SCR's drops below the output voltage, $V_{0}$, at the commutation angle $B$.

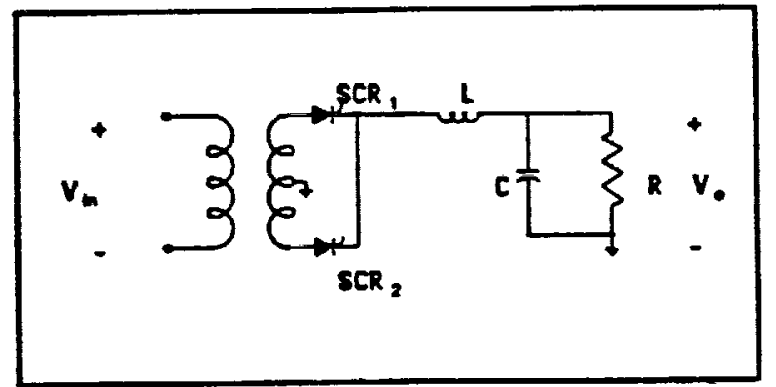

Figure 1 - Single Phase, Voltage Controlled, Full Wave Rectifier.

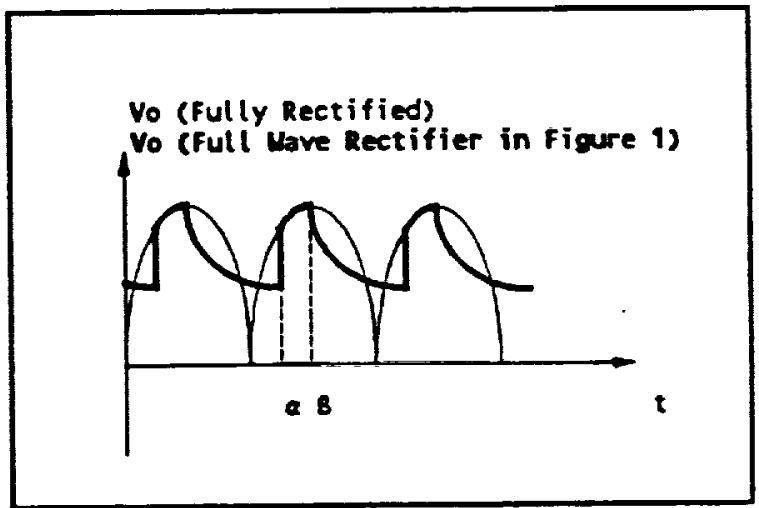

Figure 2 - Output Voltage Waveform with Fully Rectified Output Waveform.

\section{MODELLING THE RECTIFIER}

When either of the SCR's is triggered, the voltage which is applied to the input terminals of the rectifier is given by

$$
v_{1 n}(t)=v_{m} \sin (\omega, t+\alpha) u(t)
$$

where

$$
\omega_{.}=\text {system or source frequency, }
$$


and,

$$
\begin{aligned}
u(t) & =0 \text { for } t<0 \\
& =1 \text { for } t 20 .
\end{aligned}
$$

This function can be transformed into the frequency domain using the single sided, Laplace transform, which is defined by

$$
F(s)=\mathscr{L}[f(t)]=\int_{0^{-}}^{\infty} f(t) e^{-s t} d t .
$$

to give:

$$
v_{1 \alpha}(\theta)=v_{-}\left[\frac{\sin \alpha+\omega_{0} \cos \alpha}{s^{2}+\omega_{0}^{2}}\right] .
$$

The entire single phase rectifier in the frequency domain is shown in Figure 3 . The current source, $\mathrm{CV}\left(\mathrm{O}^{+}\right)$, is needed to account for the initial voltage which is present on the capacitor when the SCR is

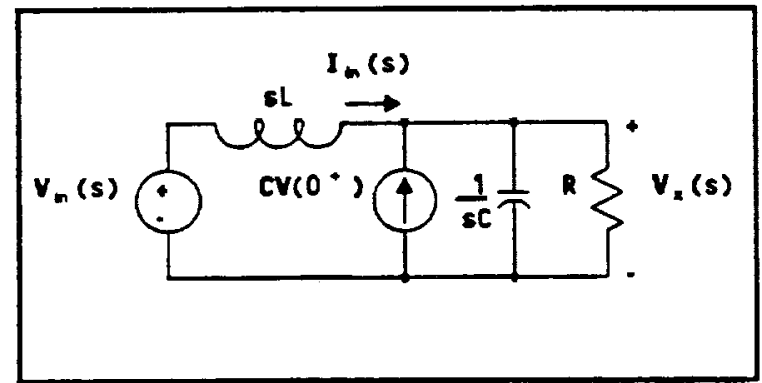

Figure 3 - Model of Rectifier in the Frequency Domain During Conduction of Either SCR.

fired at $\sigma$. Since $I_{\text {in }}(s)$ is given by

$$
I_{L}(s)=\frac{\nabla_{m}(s)-\nabla_{s}(s)}{s}
$$

$V_{x}$ (s) must be determined. This is done by writing the node equation for the top node using $V_{x}(s)$ as the unknown voltage. Solving for $V_{x}(s)$ yields:

$$
V_{z}(s)=\frac{\frac{1}{L C}\left[V_{m}\left(s \sin \alpha+\omega_{-} \cos \alpha\right)+s L C\left(s^{2}+\omega_{g}^{2}\right) v\left(0^{\circ}\right)\right]}{\left(s^{2}+\frac{s}{R C}+\frac{1}{L C}\right)\left(s^{2}+\omega_{s}^{2}\right)}
$$

Equation (1) and Equation (3) are substituted into Equation (2), the result is:

$$
I_{\omega}(s)=\frac{\frac{V_{G}}{L}\left(s+\frac{1}{K C}\right)[s \sin \alpha+\omega, \cos \alpha]-\left(s^{2}+\omega_{s}^{2}\right) v\left(0^{\prime}\right)}{\left(s^{2}+\frac{s}{X C}+\frac{1}{L C}\right)\left(s^{2}+\omega_{s}^{2}\right)}
$$

The input current to the rectifier from the $A C$ distribution system in the frequency domain, $I_{\text {in }}(s)$, is now determined. To be useful, the input current in the time domain, $I_{m}(t)$, must be found. This can be accomplished by expanding the above equation for $I_{\text {in }}$ (s) into its partial fraction form and then using the inverse Laplace transform to place it in the desired time domain form.

When Equation (4) is put into its partial fraction form, it has the form

$$
\begin{aligned}
I_{m}(s) & =\frac{K_{1} \angle \theta_{1}}{s+s_{i}^{i}}+\frac{K_{1} \angle-\theta_{1}}{s+s_{1}} \\
& +\frac{K_{2} \angle \theta_{2}}{s+s_{2}^{*}}+\frac{K_{2} \angle-\theta_{2}}{s+s_{2}}
\end{aligned}
$$

where,

$$
s_{1}=\frac{1}{2 R C}+j \frac{\sqrt{\frac{L}{L C}-\left(\frac{1}{R C}\right)^{2}}}{2},
$$

and

$$
s_{2}=j \omega_{z}
$$

The values for the numerators of roots $s_{1}{ }^{\circ}$ and $s_{2}{ }^{\circ}$ are found by:

$$
X_{1} \angle \theta_{1}=\left.\left(s+s_{i}\right) I_{m}(s)\right|_{s=-s i}
$$

and

$$
K_{2}<\theta_{2}=\left.\left(s+s_{2}^{i}\right) I_{1}\right|_{s-s_{i}}
$$


Once $K_{1} \angle \theta_{1}$ and $K_{2} \angle \theta_{2}$ are determined, then all four numerators are known since

$$
\begin{aligned}
& \boldsymbol{K}_{1}<-\theta_{1}=\left(\boldsymbol{K}_{1}<\theta_{1}\right)^{\circ} \text { and, } \\
& \boldsymbol{K}_{2}<-\theta_{2}=\left(\boldsymbol{K}_{2}<\theta_{2}\right)^{\circ} .
\end{aligned}
$$

Using the above procedure and the notation

$$
\sigma=\frac{1}{2 R C}
$$

and

$$
\lambda=\frac{\sqrt{\frac{4}{L C}-\left(\frac{1}{R C}\right)^{2}}}{2}
$$

the numerators for Equation (4) are found to be

$x_{1}<\theta_{1}=\frac{\left.\left(\frac{\nu_{-}}{l}\right)(0+j \lambda)[(\omega, \infty) \alpha-\sigma \sin \alpha)+j \lambda \sin \alpha\right)}{(j 2 \lambda)\left[\left(0^{2}+\lambda^{2}+\omega_{0}^{2}\right)-j 2 \sigma \lambda\right]}-\frac{v\left(0^{\circ}\right)}{j 2 \lambda}$

and

$$
\pi_{2}<\theta_{2}=\frac{\left(\frac{V_{\mathrm{a}}}{2 L}\right)\left(\frac{1}{R C}+j \omega_{2}\right)\left[\cos \left(\alpha-\frac{\pi}{2}\right)+j \sin \left(\alpha-\frac{\pi}{2}\right)\right]}{\left[\left(\frac{1}{L C}-\omega_{8}^{2}\right)+j \frac{\omega_{1}}{R C}\right]} .
$$

Next, the inverșe Laplace transform

$$
\alpha^{-1}\left[\frac{\Sigma \angle \theta}{s+\alpha-j \beta}+\frac{\Sigma L-\theta}{s+\alpha+j \beta}\right]=2 K_{e}-\alpha+\cos (\beta t+\theta)
$$

is used to put $I_{\text {in }}(s)$ into the time domain.

At this point, $I_{\text {in }}(t)$ is known for one period. Since the time domain form of $I_{\text {in }}(t)$ can be expressed as

$$
I_{m}(t)=c_{0}+\sum_{n=1}^{\infty} c_{n} \cos n \omega_{\rho} t+d_{n} \sin n \omega_{\rho} t,
$$

the coefficients of the series are determined by

$$
c_{0}=\frac{1}{\tau_{1}} \int_{t_{1}}^{t_{1}+\tau_{1}} f(t) d t .
$$

and

$$
\begin{aligned}
& c_{n}=\frac{2}{\tau_{1}} \int_{t_{1}}^{\tau_{1}+\tau_{0}} f(t) \cos \left(n \omega_{e} t\right) d t . \\
& d_{n}=\frac{2}{\tau_{2}} \int_{t_{1}}^{t_{1}+\tau_{0}} f(t) \sin \left(n \omega_{t} t\right) d t .
\end{aligned}
$$

Once the coefficients have been determined, they are placed in the appropriate locations of the solution vector for the computation of the next iteration of the Newton-Raphson power flow algorithm employed by HARMFLO [1-3].

\section{EXAMPLE}

The following example is offered as a means to demonstrate the theories presented in this paper. Since test results are not available at this time to provide the data needed to benchmark the results of this work, this example serves only as a sample of the techniques presented. The example is a system comprising a DC source connected to an inverter, two load busses, and lines connecting the network together. One of the loads is a

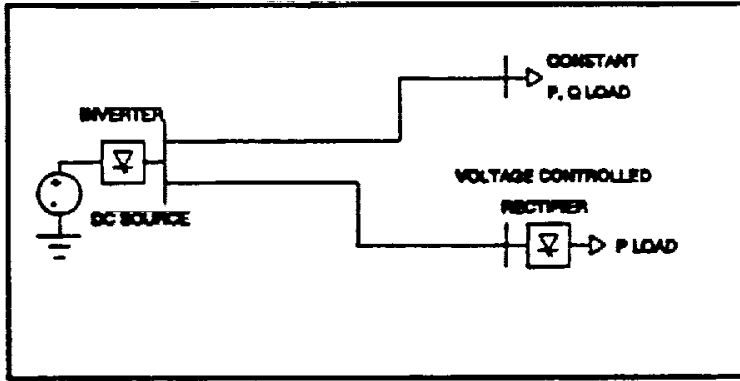

Figure 4 - Test System

conventional constant $P, Q$ load and the other is a single phase, voltage controlled rectifier. This network is shown in Figure 4. The rectifier is the same as the one shown in Figure 1. Using the component values shown in Table 1 [5], the output voltage of the voltage controlled rectifier is set at 90.0 VDC for this simulation.

The test system was analyzed using the modified HARMFLO program and the results of that analysis are shown in Table 2 . Figure 5 shows the input current of the rectifier which the technique described in this paper produces. The current, when compared to the sample fundamental voltage waveform of the system, has a frequency 
approximately equal to that of the fundamental. Calculating the natural resonant frequency of the series L-C circuit of the rectifier yields a value of $20052 \mathrm{~Hz}$. This supports the validity of the technique presented. The rectifier bus voltage for one cycle of the fundamental frequency is shown in Figure 6.

It should also be noted that the results shown in Table 2 indicate that both the source, an inverter, and the rectifier load are sources of harmonic power which are consistent with the expected behavior of the system. A computation of the fundamental power contribution, using the fundamental voltage waveform and the current waveform shown in Figure 5, yields a value of $0.76 \mathrm{~kW}$ which compares closely to the value found in Table 2.

\begin{tabular}{|c|}
\hline SYSTEM PARAMETERS \\
\hline 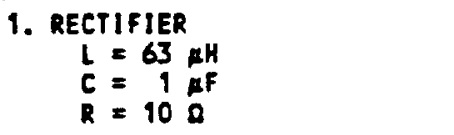 \\
\hline 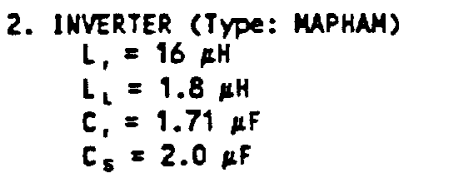 \\
\hline 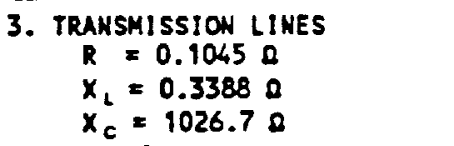 \\
\hline
\end{tabular}

Table 1 - The System Parameters of the Test System

\section{CONCLUSIONS}

The Laplace transform method proposed in this paper presents a non-iterative technique to determine the harmonic content of the rectifier current at each iteration in the solution of the harmonic power flow problem. The results indicate that the accuracy of this model appears to be quite adequate to obtain results which will assist in the analysis of space power systems.

\section{ACKNOWLEDGMENT}

The authors would like to thank The Electrical Components and Systems Branch at NASA Lewis Research Center, Cleveland, OH, for its support of the work documented in this paper. The authors would also like to thank EPRI for providing the HARMFLO source code. The constructive review by Irving G. Hansen of NASA Lewis is gratefully acknowledged.

\begin{tabular}{|c|c|c|c|c|c|}
\hline \multicolumn{6}{|c|}{ MARMFLO RESULTS } \\
\hline bus $\mathrm{kn}$ & $\begin{array}{l}\text { MARMONIC } \\
\text { ORDERR }\end{array}$ & $\begin{array}{c}v \\
\text { (pu) }\end{array}$ & 6 & $\stackrel{P}{(k W)}$ & $\stackrel{0}{\text { (kVAr) }}$ \\
\hline $\begin{array}{r}\text { 1. IMVERTER } \\
\text { TO }\end{array}$ & $\begin{array}{cc}\text { ER } & 1 \\
2 & \\
3 & \\
5 & \\
\text { TOTAL LO }\end{array}$ & $\begin{array}{l}1.000 \\
0.000 \\
0.717 \\
0.000 \\
0.053\end{array}$ & $\begin{array}{r}0.0 \\
-120.9 \\
177.5 \\
-61.6 \\
-161.7\end{array}$ & $\begin{array}{r}-4.80 \\
0.00 \\
-0.14 \\
0.00 \\
-0.01 \\
-4.95\end{array}$ & $\begin{array}{r}-2.90 \\
0.00 \\
-0.23 \\
0.00 \\
0.00 \\
-3.13\end{array}$ \\
\hline $\begin{array}{r}\text { 2. RECTIFIE } \\
\text { TO }\end{array}$ & $\begin{array}{r}\text { IER } 1 \\
2 \\
3 \\
4 \\
5 \\
\text { TOTAL LO }\end{array}$ & $\begin{array}{l}0.999 \\
0.000 \\
0.710 \\
0.000 \\
0.053\end{array}$ & $\begin{array}{r}-0.1 \\
-121.0 \\
177.7 \\
-61.5 \\
-163.7\end{array}$ & $\begin{array}{r}0.79 \\
0.00 \\
-0.38 \\
0.00 \\
0.01 \\
0.42\end{array}$ & $\begin{array}{r}0.61 \\
0.00 \\
-0.06 \\
0.00 \\
0.00 \\
0.55\end{array}$ \\
\hline 3. AC LOAD & $\begin{array}{r}1 \\
2 \\
3 \\
4 \\
5 \\
\text { TotAL LO }\end{array}$ & $\begin{array}{l}0.993 \\
0.000 \\
0.710 \\
0.000 \\
0.053\end{array}$ & $\begin{array}{r}-0.3 \\
-121.3 \\
177.3 \\
-61.8 \\
-161.9\end{array}$ & $\begin{array}{l}4.00 \\
0.00 \\
0.52 \\
0.00 \\
0.00 \\
4.52\end{array}$ & $\begin{array}{l}3.00 \\
0.00 \\
0.00 \\
0.00 \\
0.00 \\
3.00\end{array}$ \\
\hline
\end{tabular}

Table 2 - The Results of the HARMFLO Analysis of the Test System.

\section{REFERENCES}

[1] D. Xia, G. T. Heydt, "Harmonic Power Flow Studies Part 1-Formulation and Solution," IEEE Trans. on Power Apparatus and Systems, vol. PAR-101, no. 6, pp. 1257-65, June 1982.

(2) D. Xia, G. T. Heydt, "Harmonic Power Flow Studies PART 11 - Implementation and Practical Applications," IEEE Trans. on Power Apparatus and Systems, vol. PAS 101, no. 6, pp. 126670, June 1982.

[3] W. M. Grady, "Harmonic Power Flow Studies," Ph.D. Thesis, Purdue University, West LaFayette, IN, August 1983.

[4] L. A. Kraft, -Development of a Single Phase Harmonic Power Flow Program to Study the 20 kHz A.C. Power System for Large Spacecraft," 1990 Summer Faculty Fellowship Program, NASA Lewis Research Center, Cleveland, $\mathrm{OH}$. 


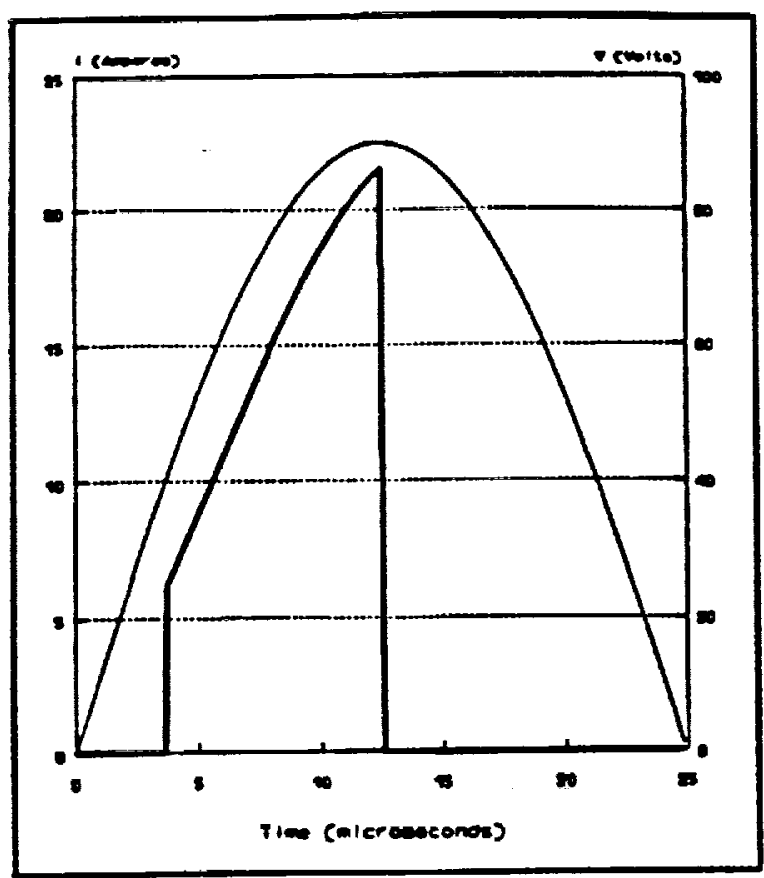

Figure 5 - Input Current of Rectifier, as Produced by Laplace Transform Method, Compared Fundamental Frequency.

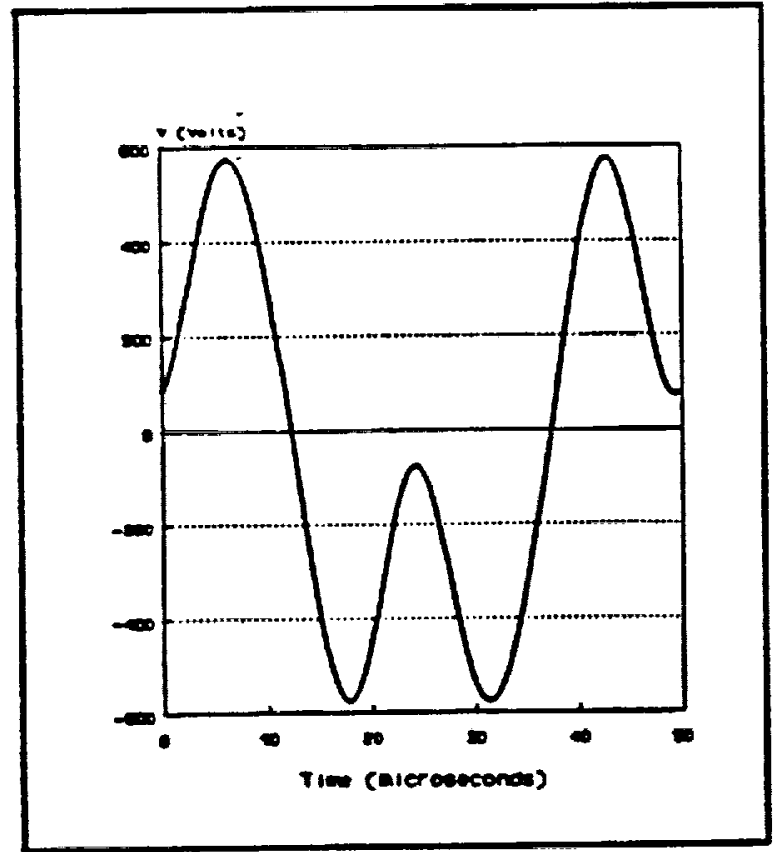

Figure 6 - Single Cycle of Rectifier's Bus Voltage.
[5]

L. A. Kraft, M. D. Kankam, "Analytical Tool to Study Power Quality of AC Power Systems for Large Spacecraft", $26^{\text {th }}$ Intersociety Energy Conversion Engineering Conference, Boston, 1991. vol. 2, Pp 20-24. 
$=$

• 
Public reporting burden for this collection of information is estimated to average 1 hour per response, inctuding the time lot reviewing instructions, searching existing dala sources, gathering and maintaining the data needed, and corrpleting and revlewing the colloction of informalion. Send comments regarding this burden estmale or any other aspoct of this Davis Highway, Sulte 1204, Arlington, VA $22202-4302$, and to the Otfice of Management and Budget, Papenwork Reduction Proper (0704-0188). Washington, DC 20503.

\begin{tabular}{|l|l|l|}
\hline 1. AGENCY USE ONLY (Leave blank) & $\begin{array}{r}\text { 2. REPORT DATE } \\
\text { September } 1992\end{array}$ & $\begin{array}{r}\text { 3. REPOAT TYPE AND DATES COVERED } \\
\text { Technical Memorandum }\end{array}$
\end{tabular}

\section{TITE AND SUBTITLE}

Modelling a Single Phase Voltage Controlled Rectifier Using Laplace Transforms
5. FUNDING NUMBERS

WU-506-41-41

\section{AUTHOR(S)}

L. Alan Kraft and M. David Kankam

\section{PERFORMING ORGANIZATIOON NAME(S) AND ADDRESS(ES)}

National Aeronautics and Space Administration

Lewis Research Center

Cleveland, Ohio 44135-3191
8. PERFORIING ORGANIZATION REPORT NUMBER

E-7552

9. SPONSOPJNG/MONTTORING AGENCY NAMES(S) AND ADDRESS(ES)

10. SPONSORING/NONITORING AGENCY REPORT NUNBER

NASA TM-106005

National Aeronautics and Space Administration

Washington, D.C. 20546-0001

\section{SUPPLEMENTARY NOTES}

Prepared for the 5th Intemational Conference on Harmonics in Power Systems, Atlanta, Georgia, September 22-25, 1992. L. Alan Kraft, Valparaiso University, Valparaiso, Indiana 46383, Grant awarded by Lewis Research Center, completed in December 1991. M. David Kankam, NASA Lewis Research Center. Responsible person, M. David Kankam, (216) 433-6143.

12a. DISTRIBUTIONAVAILABILTY STATEMENT

12b. DISTRIBUTION CODE

Unclassified - Unlimited

Subject Category 66

13. ABSTRACT (Maximum 200 words)

The development of a $20 \mathrm{kHz}, \mathrm{AC}$ power system by NASA for large space projects has spurred a need to develop models for the equipment which will be used on these single phase systems. To date, models for the AC source (i.e., inverters) have been developed. It is the intent of this paper to develop a method to model the single phase voltage controlled rectifiers which will be attached to the AC power grid as an interface for connected loads. A modified version of EPRI's HARMFLO program is used as the shell for these models. The results obtained from the model developed in this paper are quite adequate for the analysis of problems such as voltage resonance. The unique technique presented in this paper uses the Laplace transforms to determine the harmonic content of the load current of the rectifier rather than a curve fitting technique. Laplace transforms yield the coefficient of the differential equations which model the line current to the rectifier directly.

14. SUBJECT TERMS

Space power systems; Harmonic power flow; Rectifiers; Mathematical models; Laplace transforms

17. SECURTY CLASSIFICATION OF REPORT

Unclassified
18. SECUATYY CLASSIFICATION OF THIS PAGE Unclassified
19. SECURITY CLASSIFICATION OF ABSTRACT Unclassified
15. NUMBER OF PAGES

8

16. PRICE CODE $\mathrm{AO} 2$

20. LIMTTATION OF ABSTRACT 